\title{
Comprehensive intermaxillary tooth width proportion of Bangkok residents
}

Somchai Manopatanakul(a) Narumon Watanawirun ${ }^{(b)}$

(a)Australasian Board of Orthodontics, Department of Hospital Dentistry, Faculty of Dentistry, Mahidol University, Rajthewe, Bangkok, Thailand.

(b) Department of Hospital Dentistry, Faculty of Dentistry, Mahidol University, Rajthewe, Bangkok, Thailand.

\author{
Corresponding author \\ Somchai Manopatanakul \\ Department of Hospital Dentistry, \\ Faculty of Dentistry, Mahidol University \\ Yothi Street, Rajthewe \\ Bangkok - Thailand \\ ZIP Code: 10400 \\ E-mail:dtsmp@mahidol.ac.th
}

Received for publication on Jul 08, 2010

Accepted for publication on Dec 19, 2010

\begin{abstract}
Proper occlusion depends on the correct width ratio between upper and lower teeth, known as Bolton's ratio. In fact, this ratio can be calculated for each pair of teeth from the central incisor to the first permanent molar. This set of ratios, known as comprehensive cumulative percentage ratios (CPRs), can be used not only to determine which tooth or teeth have a tooth width discrepancy, but can also enable the partial graphical analysis of tooth width discrepancy when there is agenesis of certain permanent teeth. Although CPRs have been calculated for Caucasians, tooth width is known to vary depending on racial origin. Therefore, a test of differences between racial groups should be carried out. If these ratios of the Caucasians and Bangkokians are significantly different, the ratio of the Bangkokians is recommended. The objective of this study was to measure tooth size disproportion for Thai patients and to calculate a corresponding set of CPRs. Thirty-seven pairs of dental models were made from a group of Bangkok residents with normal occlusion. Mesiodistal tooth width was measured for each model. The intra- and inter-examiner measurement errors were ascertained as insignificant $(p>0.05)$. CPRs were then calculated and compared to those derived from other studies. Ten of thirteen CPRs were significantly different from corresponding values derived from Caucasians. We conclude that tooth width ratios vary between different racial groups, and therefore that these should be calculated specifically for each patient racial group.
\end{abstract}

Descriptors: Odontometry; Orthodontics, Corrective; Dentition, Permanent.

\section{Introduction}

Proper intercuspation, overjet, overbite, and alignment, depends on the correct width ratio between pairs of maxillary and mandibular teeth. ${ }^{1-3}$ Knowledge of the normal tooth width ratio can be used to guide treatment plans. For example, in the case of severe disproportion, as when there is a small upper lateral incisor, measurement of the tooth width ratio and comparison to normal values can reveal which tooth might require more esthetic dental work to achieve the optimum result. Where there is agenesis of one or more teeth, the analysis of tooth size discrepancy becomes more challenging. There is thus a need to develop a method that is able to accurately identify which tooth should be removed to achieve maximum intercuspation. ${ }^{4}$ Although some authors have ex- 
pressed the opinion that this quotient does not affect patient perception, ${ }^{5,6}$ orthodontists are nonetheless required to offer the perfect interdigitation for their patients.

Bolton's ratio is the most commonly used index of tooth width proportion. ${ }^{1}$ It is calculated as the mean of the ratio of the six upper and lower teeth from the permanent central incisor to the first permanent molar. The posterior ratio and overall ratio are also used. Although each of these ratios has been studied extensively for a range of different racial ${ }^{7-10}$ and malocclusion groups, ${ }^{11-16}$ it is not clear whether their clinical application in these studies was appropriate. To clarify this issue, Tonn specifically analyzed the ratio of the upper and lower premolars. ${ }^{17}$ Similarly, Bowles examined the ratio of the canines and premolars. ${ }^{18}$ Ultimately, ratios have been established for each matching pair of upper and lower teeth. The most comprehensive listing of cumulative percentage ratios (CPRs) was published by Ho and Freer, who listed 13 CPRs that were categorized as six antimere ratios, five buccal segment ratios, and two additional ratios. ${ }^{19}$ The definition of each CPR is listed in Table 1.

Tooth width is strongly influenced by genetic factors, and is known to vary significantly among different genders and races. ${ }^{20-21}$ The population of Bangkok is composed of people with origins from each region of Thailand. Although the majority of Bangkokians are of Thai ethnic background, centuries of migration and invasion have resulted in a mixing in of many other ethnicities, as has subse-

Table 1 - Variables of Ho and Freer's study. ${ }^{19}$

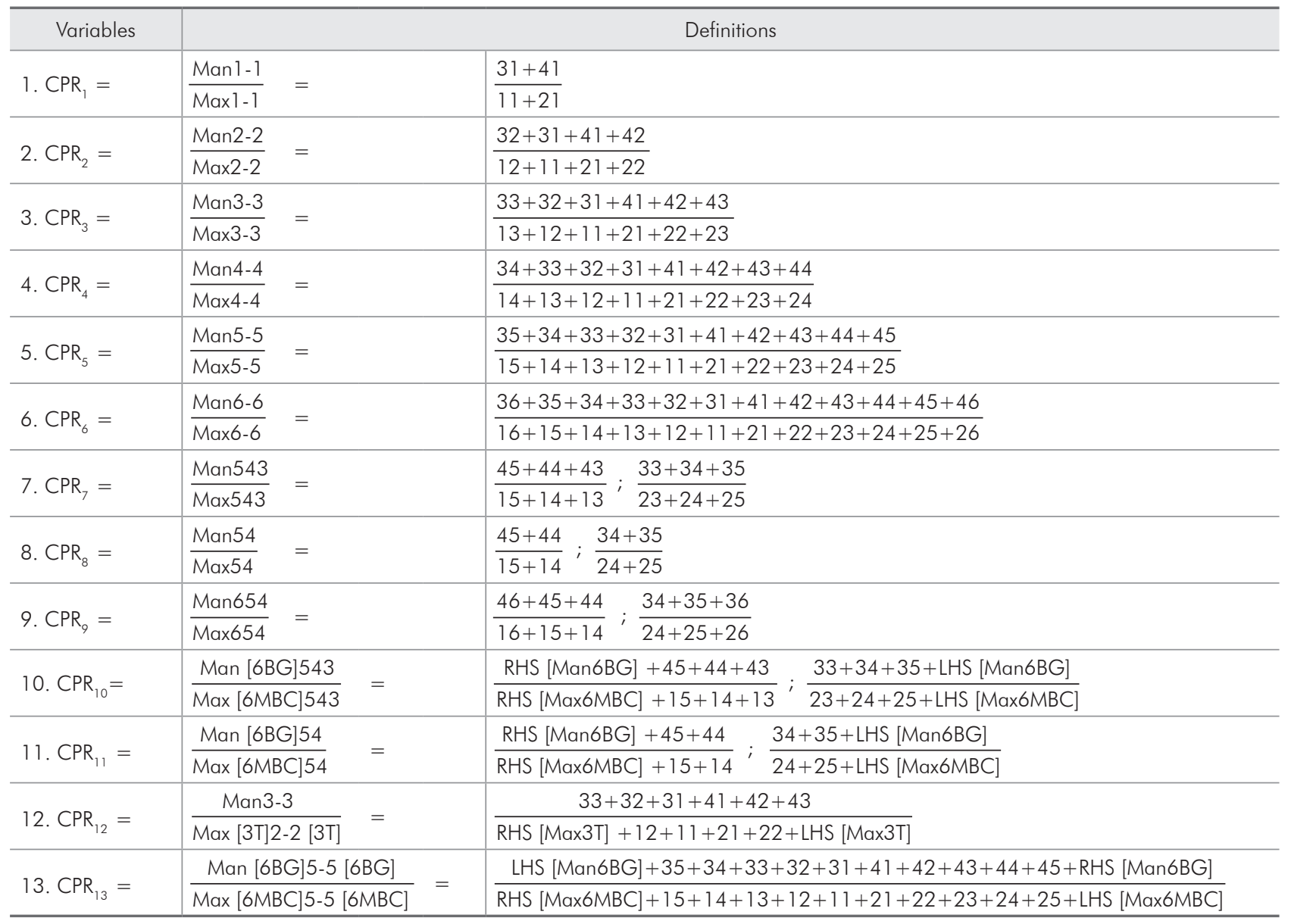

All variables calculated as a percentage. Man, mandibular tooth; Max, maxillary tooth; Man[6MB], distance from buccal groove to the mesial contact area of the lower first molar; Max[6MBC], distance from tip of mesiobuccal cusp to the mesial contact area of the upper first molar; Max[3T], distance from tip of upper canine cusp to the mesial contact area of the upper canine; RHS, right hand side; LHS, left hand side 
quent integration of immigrants and travelers from South and Southeast Asia as well as Europe. More recently, intermarriages of Thais with Caucasian, Japanese, Chinese, and Middle East people have become more common. As a result, the ethnic background of Bangkokians is continually evolving. ${ }^{22-23}$ This circumstance might be expected to affect the normal range of tooth widths in this population.

The aim of this study was to establish a complete set of comprehensive cumulative percentage ratios for Bangkokians, and to determine whether these should supplant the current criteria.

\section{Materials and methods}

Impressions were taken from a group of Bangkok residents with normal occlusion. The inclusion criteria for the study were:

1. full eruption of all permanent teeth, aside from the second and third molars;

2. normal occlusion, with Class I molar relationship;

3. normal alignment, with no crowding or spacing;

4. normal tooth size and shape;

5. normal overjet and overbite;

6. no fillings, or proximal fillings in good condition; and

7. the patient's signed written consent.

From 495 subjects evaluated, 37 met the criteria for selection. The average age of patients was 18.5 years, ranging from 11 to 30 years.

Since tooth size is known to vary among people of different ethnicities, the ethnic origin of each sample was recorded and is shown in Table 2. The most numerous subgroup in the sample was Thai with a mixture of Chinese and Thai-Chinese. The ethnic backgrounds of all patients who reported their ethnicity to be Thai are shown in Table 3.

The impressions were poured with stone and the bases were polished as dental models. Mitutoyo digimatic calipers were used to measure the mesiodistal width of each tooth to an accuracy of $0.01 \mathrm{~mm}$ (Mitutoyo Corporation, Kanagawa, Japan). The parameters for tooth width measurement were as described by Ho and Freer, ${ }^{19}$ and are listed in Table 1. Two dentists conducted tooth width
Table 2 - Ethnic background of patients.

\begin{tabular}{l|c|c}
\hline Ethnic origin & N & Percentage \\
\hline Thai & 19 & 51 \\
\hline Chinese & 6 & 16 \\
\hline Thai-Chinese & 1 & 3 \\
\hline Not known & 11 & 30 \\
\hline Total & 37 & 100 \\
\hline
\end{tabular}

Table 3 - Background of patients who reported Thai ethnic origin.

\begin{tabular}{l|c|c}
\hline Region of Thailand & N & Percentage \\
\hline Northeastern & 10 & 53.0 \\
\hline North & 2 & 10.5 \\
\hline Central & 2 & 10.5 \\
\hline Eastern & 1 & 5.0 \\
\hline Bangkok & 4 & 21.0 \\
\hline Total & 19 & 100.0 \\
\hline
\end{tabular}

measurement in parallel. All measurements were additionally reviewed by an orthodontist experienced in tooth width measurement (SM).

We also carried out a literature search to retrieve previous studies to whose results our values could be compared. Previous studies carried out on systematic tooth size discrepancy were reviewed. All studies conducted on Bangkok residents were also reviewed. The criteria included studies that were well documented and peer reviewed. Studies that were original, well known, and reported commonly used ratios and specific posterior ratios were included. Six studies met the criteria.

\section{Results}

The mean value of every CPR plus or minus 2 standard deviations is shown in Table 4. To assess variability, each examiner made duplicate measurements on ten pairs of models. When the first and replicate measurements were compared using the paired t-test, no significant difference in the two sets of measurements were found for either examiner $(\mathrm{p}>0.05)$. A similar comparison was made between the measurements made by 2 examiners on the same set of models, and again no significant difference in 
the measured values was found $(\mathrm{p}>0.05)$.

We used the t-test to compare our results with those reported by Ho and Freer. ${ }^{19}$ The results of this analysis are shown in Table 5. With the exception

Table 4 - Mean cumulative percentage ratios plus and minus two standard deviations.

\begin{tabular}{c|c|c|c}
\hline Variables & Mean-2 S.D. & Mean & Mean + 2 S.D. \\
\hline $\mathrm{CPR}_{1}$ & 55.62 & 61.34 & 67.06 \\
\hline $\mathrm{CPR}_{2}$ & 66.53 & 72.01 & 77.49 \\
\hline $\mathrm{CPR}_{3}$ & 72.73 & 77.09 & 81.45 \\
\hline $\mathrm{CPR}_{4}$ & 78.89 & 82.41 & 85.93 \\
\hline $\mathrm{CPR}_{5}$ & 82.57 & 86.33 & 90.09 \\
\hline $\mathrm{CPR}_{6}$ & 88.18 & 91.66 & 95.14 \\
\hline $\mathrm{CPR}_{7}$ & 90.98 & 96.64 & 102.30 \\
\hline $\mathrm{CPR}_{8}$ & 94.94 & 102.66 & 110.38 \\
\hline $\mathrm{CPR}_{9}$ & 99.34 & 105.76 & 112.18 \\
\hline $\mathrm{CPR}_{10}$ & 98.76 & 106.43 & 114.19 \\
\hline $\mathrm{CPR}_{11}$ & 106.79 & 116.01 & 125.23 \\
\hline $\mathrm{CPR}_{12}$ & 85.79 & 91.77 & 97.75 \\
\hline $\mathrm{CPR}_{13}$ & 90.13 & 93.77 & 97.41 \\
\hline
\end{tabular}

Table 5 - A comparison of tooth ratios from the present study and that of Ho and Freer. ${ }^{19}$

\begin{tabular}{|c|c|c|c|c|c|}
\hline \multirow[b]{2}{*}{ Variables } & \multicolumn{2}{|c|}{ Mean } & \multicolumn{2}{|c|}{ S.D. } & \multirow[b]{2}{*}{$\begin{array}{l}\text { Statistical } \\
\text { significance }\end{array}$} \\
\hline & $\begin{array}{l}\text { Ho and } \\
\text { Freer's } \\
\text { study }\end{array}$ & $\begin{array}{l}\text { Present } \\
\text { study }\end{array}$ & $\begin{array}{l}\text { Ho and } \\
\text { Freer's } \\
\text { study }\end{array}$ & $\begin{array}{l}\text { Present } \\
\text { study }\end{array}$ & \\
\hline $\mathrm{CPR}_{1}$ & 63.69 & 61.34 & 2.89 & 2.86 & $* *$ \\
\hline $\mathrm{CPR}_{2}$ & 74.51 & 72.01 & 2.59 & 2.74 & $* *$ \\
\hline $\mathrm{CPR}_{3}$ & 78.73 & 77.09 & 2.10 & 2.18 & $* *$ \\
\hline $\mathrm{CPR}_{4}$ & 84.04 & 82.41 & 1.73 & 1.76 & $* *$ \\
\hline $\mathrm{CPR}_{5}$ & 88.09 & 86.33 & 1.69 & 1.88 & $* *$ \\
\hline $\mathrm{CPR}_{6}$ & 91.98 & 91.66 & 1.58 & 1.74 & NS \\
\hline $\mathrm{CPR}_{7}$ & 97.72 & 96.64 & 2.63 & 2.83 & $*$ \\
\hline $\mathrm{CPR}_{8}$ & 103.71 & 102.66 & 3.62 & 3.86 & $* *$ \\
\hline $\mathrm{CPR}_{9}$ & 104.56 & 105.76 & 2.86 & 3.21 & * \\
\hline $\mathrm{CPR}_{10}$ & 106.83 & 106.43 & 3.10 & 3.88 & NS \\
\hline $\mathrm{CPR}_{11}$ & 116.17 & 116.01 & 4.32 & 4.61 & NS \\
\hline $\mathrm{CPR}_{12}$ & 96.44 & 91.77 & 2.93 & 2.99 & $* *$ \\
\hline $\mathrm{CPR}_{13}$ & 94.37 & 93.77 & 1.96 & 1.82 & $* *$ \\
\hline
\end{tabular}

${ }^{*} p<0.05,{ }^{* *} p<0.01$ of CPR 6, 10, and 11, each of the CPR values we calculated differed significantly from those reported by Ho and Freer. ${ }^{19}$

We extended our comparison to a number of additional previous studies, comparing the sample size, mean, and standard deviation of the ratios reported by each one of them (Table 6). ${ }^{1,17-19,24,25}$ Using the t-test, no significant difference was found between the overall ratios we calculated and those reported by other studies. Notably, although Dechkunakorn et al. studied a patient population from the same area as that of our patients, the anterior ratio they reported was significantly different from our result. However, no significant difference was found between the corresponding posterior ratios. ${ }^{25}$

\section{Discussion}

In this study, we have produced a comprehensive set of tooth width ratios for a group of Bangkok residents with normal occlusion.

Ho and Freer reported CPRs for all teeth required for a proper occlusion. ${ }^{2,19}$ This provided a valuable tool for the clinician, as it allowed the individual teeth responsible for malocclusion to be identified. Bolton proposed that tooth widths more than two standard deviations greater or smaller than the mean be considered out of range. ${ }^{1}$ In accordance, we calculated these values for Bangkok residents (Table 4).

We compared our results to previous studies both of Caucasian and Thai patients. The anterior ratio we derived differed significantly from that of all previous studies. The posterior ratio of this study was also statistically different from the posterior ratio of different ethnic groups. Even when the anterior ratios were compared with those found for a population of the same area nine years earlier, they were significantly different. Therefore, we suggest that clinicians use the new values we have reported here.

Although this study might be criticized for having a small sample size, we emphasize that we applied strict inclusion criteria to a patient pool that was initially much larger (from 495 subjects, only 37 with perfect occlusion were included). We note also that the comprehensive ratio is not the only factor that should be considered when teeth are re- 
Table 6 - Comparison of percentage of tooth width ratios between the present and previous studies.

\begin{tabular}{|c|c|c|c|c|c|}
\hline Variables & Studies & $N$ & Mean & S.D. & Statistical significance \\
\hline \multirow{4}{*}{$\begin{array}{l}\text { Anterior ratio } \\
\frac{(\text { Man3-3) }}{(\text { Max3-3) }}\end{array}$} & Bolton (1958)' & 55 & 77.20 & 1.65 & NS \\
\hline & Ho and Freer (1994) ${ }^{19}$ & 60 & 78.70 & 2.10 & $* * *$ \\
\hline & Dechkunakorn (1995) ${ }^{25}$ & 100 & 78.53 & 2.34 & $* * *$ \\
\hline & Present study & 37 & 77.09 & 2.18 & \\
\hline \multirow{4}{*}{$\begin{array}{l}\text { Overall ratio } \\
\frac{(\text { Man6-6) }}{(\text { Max6-6) }}\end{array}$} & Bolton (1958) ${ }^{1}$ & 55 & 91.30 & 1.91 & NS \\
\hline & Ho and Freer $(1994)^{19}$ & 60 & 92.00 & 1.58 & NS \\
\hline & Dechkunakorn (1995) ${ }^{25}$ & 100 & 92.00 & 1.68 & NS \\
\hline & Present study & 37 & 91.66 & 1.74 & \\
\hline \multirow{4}{*}{$\begin{array}{l}\text { Posterior ratio } \\
\frac{(\text { Man4,5,6) }}{(\operatorname{Max} 4,5,6)}\end{array}$} & Lundstrom $(1954)^{* 24}$ & 68 & 104.90 & 3.08 & NS \\
\hline & Ho and Freer (1994) ${ }^{19}$ & 60 & 104.60 & 2.86 & $* *$ \\
\hline & Dechkunakorn (1995) ${ }^{25}$ & 100 & 104.90 & 2.17 & NS \\
\hline & Present study & 37 & 105.76 & 3.21 & \\
\hline \multirow{3}{*}{$\frac{(\text { Man54) }}{(\text { Max54) }}$} & Tonn $(1937)^{* 17}$ & 50 & 104.20 & 2.30 & $* * *$ \\
\hline & Ho and Freer (1994) ${ }^{19}$ & 60 & 103.70 & 3.63 & $* * *$ \\
\hline & Present study & 37 & 102.66 & 3.86 & \\
\hline \multirow{3}{*}{$\frac{(\text { Man543) }}{(\text { Max543) }}$} & Bowles (1970) ${ }^{18}$ & 30 & 96.60 & 1.50 & NS \\
\hline & Ho and Freer $(1994)^{19}$ & 60 & 97.70 & 2.60 & $* *$ \\
\hline & Present study & 37 & 96.64 & 2.83 & \\
\hline
\end{tabular}

*value derived and calculated from this study, ${ }^{* *} p<0.05,{ }^{* * *} p<0.01$

quired to fit for perfect occlusion; the labio-lingual tooth thickness, inclination, and interincisal angle must also be included. ${ }^{5,6}$ These factors require verification to identify the priority of clinical relevance.

\section{Conclusion}

The maxillary and mandibular tooth width ratios have been shown to affect occlusal interdigitation. However, as these ratios were initially derived by Ho and Freer from Caucasian children, it is questionable whether they can be accurately applied to

\section{References}

1. Bolton WA. Disharmony in tooth size and its relation to the analysis and treatment of malocclusion. Angle Orthod. 1958;28(3):113-30.

2. Ho CT, Freer TJ. Clinical application of the graphical analysis of tooth width discrepancy. Aust Orthod J. 1994 Mar;13(3):137-43.

3. Endo T, Ishida K, Shundo I, Sakaeda K, Shimooka S. Effects of premolar extractions on Bolton overall ratios and tooth- patients of other ethnic origin. Here, we have recalculated tooth width ratios for Bangkok residents with normal occlusion, and determined that the majority of CPRs are different from those derived from Caucasian samples, and from those derived from a similar patient population 9 years earlier. ${ }^{19}$

\section{Acknowledgements}

Dr. Ittigon Law's assistance with tooth width measurement is gratefully appreciated.

size discrepancies in a Japanese orthodontic population. Am J Orthod Dentofacial Orthop. 2010 Apr;137(4):508-14.

4. Bayram M, Ozer M. Mandibular incisor extraction treatment of a Class I malocclusion with Bolton discrepancy: a case report. Eur J Dent. 2007Jan;1(1):54-9.

5. Othman SA, Harradine NW. Tooth-size discrepancy and Bolton's ratios: a literature review. J Orthod. 2006 Mar;33(1):45-51. 
6. Cordato MA. A simple mathematical study of anterior dental relations: part I. Aust Orthod J. 1995 Mar;13(4):249-52.

7. Endo T, Shundo I, Abe R, Ishida K, Yoshino S, Shimooka S. Applicability of Bolton's tooth size ratios to a Japanese orthodontic population. Odontology. 2007 Jul;95(1):57-60. Epub 2007 Jul 25.

8. Paredes V, Gandia JL, Cibrian R. Do Bolton's ratios apply to a Spanish population? Am J Orthod Dentofacial Orthop. 2006 Mar;129(3):428-30.

9. Uysal T, Sari Z. Intermaxillary tooth size discrepancy and mesiodistal crown dimensions for a Turkish population. Am J Orthod Dentofacial Orthop. 2005 Mar;128(2):226-30.

10. Al-Omari IK, Al-Bitar ZB, Hamdan AM. Tooth size discrepancies among Jordanian school children. Eur J Orthod. 2008 Oct;30(5):527-31. Epub 2008 Jul 5.

11. Araujo E, Souki M. Bolton anterior tooth size discrepancies among different malocclusion groups. Angle Orthod. 2003 Jun;73(3):307-13.

12. Nie Q, Lin J. Comparison of intermaxillary tooth size discrepancies among different malocclusion groups. Am J Orthod Dentofacial Orthop. 1999 Nov;116(5):539-44.

13. Freeman JE, Maskeroni AJ, Lorton L. Frequency of Bolton tooth-size discrepancies among orthodontic patients. Am J Orthod Dentofacial Orthop. 1996 Jul;110(1):24-7.

14. Sperry TP, Worms FW, Isaacson RJ, Speidel TM. Tooth-size discrepancy in mandibular prognathism. Am J Orthod. 1977 Aug;72(2):183-90.

15. Wedrychowska-Szulc B, Janiszewska-Olszowska J, Stepien P. Overall and anterior Bolton ratio in Class I, II, and III orthodontic patients. Eur J Orthod. 2010 Jun;32(3):313-8. Epub 2009 Dec 16.

16. Oktay H, Ulukaya E. Intermaxillary tooth size discrepancies among different malocclusion groups. Eur J Orthod. 2010 Jun;32(3):307-12. Epub 2009 Sep 3.

17. Tonn P. Uber die mesio-distalen Zahnbreitenrelationen Oberkiefers zu den entsprechenden des Unterkiefers bei normalen and anormalen Okklusion [dissertation]. Berlin (Germany): Humboldt-Universitat; 1937. 46 p.

18. Bowles RM. Evaluation of tooth size relationships in various intradental and interdental arch segments. Am J Orthod. 1970 Apr;57(4):415.

19. Ho CT, Freer TJ. The graphical analysis of tooth width discrepancy. Aust Orthod J. 1994 Mar;13(2):64-70.

20. Garn SM. Lewis AB, Kerewsky RS. Sex differences in tooth size. J Dent Res. 1964 Mar;43:306.

21. Barrett MJ, Brown T, Macdonald MR. Dental observations on Australian aborigines: mesiodistal crown diameters of permanent teeth. Aust Dent J. 1965 Sep;44(5):912-20.

22. Singhakachen W. Demography. Bangkok: Sritongkum Publishing; 2001. $200 \mathrm{p}$.

23. Jaroontham J, Godfrey K. Mixed dentition space analysis in a Thai population. Eur J Orthod. 2000 Apr;22(2):127-34.

24. Lundstrom A. Intermaxillary tooth width ratio and tooth alignment and occlusion. Acta Odontol Scand. 1955 Feb;12(34):265-92.

25. Dechkunakorn S, Chaiwat J, Sawaengkit P, Anuwongnukroh N, Nisalak P. Dental arch in normal occlusion part I: Size of teeth and percentage ratio between lower and upper teeth. J Dent Assoc Thai.1995 Jul;45(4):159-67. 